\title{
Synthesis and Structural Studies of Mn(II), Co(III), and Ni(II) Complexes with Schiff Base Ligands Derived from 2-Acetylpyridine
}

\author{
Bon Kweon Koo* \\ Department of Chemistry, Catholic University of Daegu, Gyeongbuk 712-702, Korea. *E-mail: bkkoo@cu.ac.kr \\ Received January 5, 2011, Accepted March 3, 2011
}

Key Words : Mn(II)-, Co(III)-, Ni(II)- complex, Schiff base, Crystal structure

Schiff bases containing N, S donor atoms and their metal complexes have received considerable attention owing to their potent biological activity as anti-fungals, ${ }^{1-4}$ anti-virals, ${ }^{5}$ anti-malarials, ${ }^{6,7}$ and most notably, as anti-tumor agents. ${ }^{8-10}$ For example, thiosemicarbazones (tsc) show a wide range of biological properties depending on the parent aldehyde or ketone; if these are heterocyclic aromatic system, their nature seems to enhance their activity. ${ }^{11}$ Tsc usually bind to a metal ion as bidentate $N, S$-donor ligands, when a third donor site is incorporated into the ligands, like tsc of 2-acetylpyridine, normally $N, N, S$-tricoordination takes place. The $\pi$ delocalization of charge and the configurational flexibility of their molecular chain can give rise to a great variety of coordination modes. In this work, the schiff base (acpymdtcH) derived from 2-acetylpyridene and $S$-methyldithiocarbazate was taken as trifunctional $(N, N, S)$ monobasic ligand. This ligand shown in thione (I) and thiol (II) form is of important because their coordination mode.

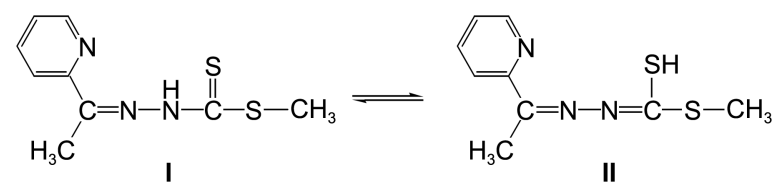

Although many metal-schiff base complexes have been reported, The 1D, 2D, and 3D networks of coordination polymers linked through the bridging of ligands such as dicyanamide, $\mathrm{N}(\mathrm{CN})_{2}{ }^{-}$as coligand have been little published. ${ }^{12,13}$ In the process of working to extend the dimensionality of the metal-schiff base complexes using benzilic acid (BA) as a bridging ligand, we obtained three different metal - Mn(II), Co(III), and Ni(II) - complexes of acetylpyridine based dithiocarbazate ligand. Therefore, we report here the synthesis and crystal structures of three $\mathrm{Mn}$ (II), Co(III), and $\mathrm{Ni}(\mathrm{II})$ complexes with acpy-mdtc ${ }^{-}$ligand. Thermal properties of the complexes are also discussed.

\section{Experimental Section}

All chemicals are commercially available and were used as received without further purification. Elemental analyses (CHNS) were performed on a Vario EL EA-Elementar Analyzer. Infrared spectra were recorded in the range from 4000 to $400 \mathrm{~cm}^{-1}$ on a Mattson Polaris FT-IR Spectrophoto- meter using $\mathrm{KBr}$ pellets. Thermogravimetric (TG) and differential thermal analysis (DTA) were performed on a Shimadzu DTG-60 instrument with a heating rate of 10 ${ }^{\circ} \mathrm{C} \cdot \min ^{-1}$.

Preparation of [Mn(acpy-mdtc)(BA) (1). To a methanolic solution $(20 \mathrm{~mL})$ of acpy-mdtcH ligand $(0.225 \mathrm{~g}, 1$ mmol) was added $\mathrm{Mn}\left(\mathrm{ClO}_{4}\right)_{2} \cdot \mathrm{H}_{2} \mathrm{O}(0.254 \mathrm{~g}, 1 \mathrm{mmol})$. To the resulting solution was added a methanolic solution $(3 \mathrm{~mL})$ of BA $(0.228 \mathrm{~g}, 1 \mathrm{mmol})$ and triethylamine $(0.101 \mathrm{~g}, 1 \mathrm{mmol})$. The solution turned immediately to black and was stirred futher for $3 \mathrm{~h}$ to yield a brown solid. The solid was filtered, washed with methanol and dried in air. Yield 52\% (0.260 g) based on Mn. Anal. calcd. for $\mathrm{C}_{23} \mathrm{H}_{21} \mathrm{~N}_{3} \mathrm{O}_{3} \mathrm{~S}_{2} \mathrm{Mn}$ : C, 54.65; H, 4.19; N, 8.31; S, 12.69. Found: C, 54.24; H, 4.29; N, 8.27; S, 12.78\%. IR (KBr pellet, $\mathrm{cm}^{-1}$ ): $3084(\mathrm{w}), 3061(\mathrm{w})$, 1614 (s), 1592 (s), 1429 (m), 1408 (vs), 1370 (m), 1304 (m), $1245(\mathrm{~m}), 1009(\mathrm{~m}), 934(\mathrm{~m}), 803(\mathrm{~m}), 779(\mathrm{~m}), 756(\mathrm{~m})$, $698(\mathrm{~m}), 671(\mathrm{~m})$.

The filtrate was kept at room temperature for a week to isolate black single crystals (block) suitable for X-ray diffraction: [Mn(acpy-mdtc) $)_{2}$ (2), yield 18\% (0.089 g) based on Mn.

Preparation of $\left[\mathrm{Co}(\mathrm{acpy}-\mathrm{mdtc})_{2}\right] \mathrm{ClO}_{4} \cdot \mathbf{0 . 5 H}_{2} \mathrm{O}$ (3). The synthesis of $\mathbf{3}$ was similar to that of $\mathbf{1}$ except that $\mathrm{Co}\left(\mathrm{ClO}_{4}\right)_{2} \cdot 6 \mathrm{H}_{2} \mathrm{O}(0.366 \mathrm{~g}, 1 \mathrm{mmol})$ was used instead of $\mathrm{Mn}\left(\mathrm{ClO}_{4}\right)_{2} \cdot \mathrm{H}_{2} \mathrm{O}(0.254 \mathrm{~g}, 1 \mathrm{mmol})$. Black crystals (needle) of 3 suitable for X-ray diffraction were isolated from the filtrate with $4 \%(0.024 \mathrm{~g})$ yield based on Co. Anal. Calcd. for $\mathrm{C}_{18} \mathrm{H}_{21} \mathrm{~N}_{6} \mathrm{O}_{4.5} \mathrm{~S}_{4} \mathrm{ClCo}$ : C, 35.09; H, 3.44; N, 13.64; $\mathrm{S}$, 20.82. Found: C, 35.10; H, 3.48; N, 13.62; S, 20.71\%. IR $\left(\mathrm{KBr}\right.$ pellet, $\left.\mathrm{cm}^{-1}\right)$ : $3568(\mathrm{w}), 3111(\mathrm{w}), 3083(\mathrm{w}), 1600(\mathrm{w})$, 1439 (sh), 1415 (vs), 1315 (m), 1081 (vs), 1038 (vs), 949 (m), $767(\mathrm{w}), 621(\mathrm{w})$.

Preparation of $\left[\mathrm{Ni}_{2}\left(\mathbf{a c p y}-\mathrm{mdtc}_{3}\right] \mathrm{ClO}_{4} \cdot \mathrm{CH}_{3} \mathrm{OH}\right.$ (4). The synthesis of $\mathbf{4}$ was similar to that of $\mathbf{1}$ except that $\mathrm{Ni}\left(\mathrm{ClO}_{4}\right)_{2} \cdot 6 \mathrm{H}_{2} \mathrm{O}(0.366 \mathrm{~g}, 1 \mathrm{mmol})$ was used instead of $\mathrm{Mn}\left(\mathrm{ClO}_{4}\right)_{2} \cdot 6 \mathrm{H}_{2} \mathrm{O}$. Black block-type crystals of 4 suitable for X-ray diffraction were isolated from the filtrate with $6 \%(0.028 \mathrm{~g})$ yield based on $\mathrm{Ni}$. Anal. Calcd. for $\mathrm{C}_{28} \mathrm{H}_{34} \mathrm{~N}_{9} \mathrm{O}_{5} \mathrm{~S}_{6} \mathrm{ClNi}_{2}$ : C, 36.48; H, 3.72; N, 13.67; S, 20.87. Found: C, 36.35; H, 3.75; N, 13.72; S, 20.75\%. IR ( $\mathrm{KBr}$ pellet, $\mathrm{cm}^{-1}$ ): $3421(\mathrm{w}), 3074(\mathrm{w}), 1649$ (s), 1599 (m), 1448 (s), 1386 (s), 1302 (vs), 1096 (s), 1043 (s), 940 (s), 749 (m), $698(\mathrm{~m})$. 
Table 1. Crystal data and structure refinement for the complexes of $\mathbf{3}$ and $\mathbf{4}$

\begin{tabular}{|c|c|c|}
\hline Complex & 3 & 4 \\
\hline Empirical formula & $\mathrm{C}_{18} \mathrm{H}_{21} \mathrm{~N}_{6} \mathrm{O}_{4.5} \mathrm{~S}_{4} \mathrm{ClCo}$ & $\mathrm{C}_{28} \mathrm{H}_{34} \mathrm{~N}_{9} \mathrm{O}_{5} \mathrm{~S}_{6} \mathrm{ClNi}_{2}$ \\
\hline Formula weight & 616.05 & 921.87 \\
\hline $\mathrm{T}(\mathrm{K})$ & $200(2)$ & $200(2)$ \\
\hline$\lambda(\AA)$ & 0.71073 & 0.71073 \\
\hline Crystal system & monoclinic & Triclinic \\
\hline Space group & $\mathrm{C} 2 / \mathrm{c}$ & P-1 \\
\hline$a(\AA)$ & $35.1792(14)$ & $11.1918(6)$ \\
\hline$b(\AA)$ & $7.8585(3)$ & $11.2122(6)$ \\
\hline$c(\AA)$ & $23.1578(9)$ & $16.0317(9)$ \\
\hline$\alpha\left(^{\circ}\right)$ & & $75.8940(10)$ \\
\hline$\beta\left(^{\circ}\right)$ & $128.5750(10)$ & $88.0130(10)$ \\
\hline$\gamma\left({ }^{\circ}\right)$ & & $75.9800(10)$ \\
\hline$V\left(\AA^{3}\right)$ & $5005.1(3)$ & $1892.32(18)$ \\
\hline$Z$ & 8 & 2 \\
\hline$\mu\left(\mathrm{mm}^{-1}\right)$ & 1.167 & 1.447 \\
\hline$F(000)$ & 2512 & 948 \\
\hline$\theta\left({ }^{\circ}\right)$ & 1.48 to 28.28 & 1.31 to 26.00 \\
\hline \multirow[t]{3}{*}{ Absorption correction } & multi-scan & multi-scan \\
\hline & $\mathrm{T}_{\min }=0.774$ & $\mathrm{~T}_{\min }=0.687$ \\
\hline & $\mathrm{T}_{\max }=0.845$ & $\mathrm{~T}_{\max }=0.838$ \\
\hline Limiting indices & $\begin{array}{l}-46 \leq h \leq 45,-10 \leq k \leq 10, \\
-30 \leq l<28\end{array}$ & $\begin{array}{l},-7 \leq h \leq 13,-13 \leq k \leq 13, \\
-18 \leq l<19\end{array}$ \\
\hline Reflections collected & 17194 & 11926 \\
\hline Independent reflections & $\mathrm{s} 6129[\mathrm{R}(\mathrm{int})=0.0737]$ & $7350[\mathrm{R}$ (int) $=0.0240]$ \\
\hline $\begin{array}{l}\text { Observed reflections } \\
{[I \geq 2 \sigma(I)]}\end{array}$ & 3708 & 5777 \\
\hline Goodness-of-fit on $F^{2}$ & 1.140 & 1.148 \\
\hline$R_{1}[I \geq 2 \sigma(I)]$ & 0.0756 & 0.0634 \\
\hline$w R_{2}[I \geq 2 \sigma(I)]$ & 0.2006 & 0.1618 \\
\hline$R_{1}$ & 0.1243 & 0.0886 \\
\hline$w R_{2}$ & 0.2914 & 0.2216 \\
\hline $\begin{array}{l}\text { Largest peak and hole } \\
\left(\mathrm{e} \AA^{-3}\right)\end{array}$ & 2.222 and -1.200 & 1.808 and -1.207 \\
\hline
\end{tabular}

X-ray Structure Determination. Single crystals of 2-4 were obtained by the method described in the above procedures. Structural measurement for the complexes was performed on a Bruker SMART APEX CCD diffractometer using graphite monochromatized Mo-K $\alpha$ radiation $(\lambda=$ $0.71073 \AA)$ at the Korea Basic Science Institute. A multiscan absorption correction was applied using the SADABS program..$^{14}$ The structures were solved by direct method and refined on $F^{2}$ by full-matrix least-squares procedures using the SHELXTL programs, ${ }^{15}$ respectively. All non-hydrogen atoms were refined using anisotropic thermal parameters. $\mathrm{CH}$ Hydrogen atoms were included in the structure factor calculation at idealized positions by using a riding model, but not refined. Images were created with the ORTEP. ${ }^{16}$ The crystallographic data for the complexes of $\mathbf{3}$ and $\mathbf{4}$ are listed in Table 1, respectively.

Crystallographic data for the structural analysis have been deposited at the Cambridge Crystallographic Data Center: 805045 (3), and 805047 (4). Copies of this information may be obtained free of charge from: The director, CCDC, 12 Union Road, Cambridge, CB2 1EZ, UK (Fax: +44-1223336-003; E-mail: deposit@ccdc.cam.ac.uk or www: http:// www.ccdc.cam. ac.uk).

\section{Results and Discussion}

The complexes of 1-4 were prepared from the methanolic solution of $\mathrm{M}\left(\mathrm{ClO}_{4}\right)_{2} \cdot \mathrm{xH}_{2} \mathrm{O}(\mathrm{M}=\mathrm{Mn}, \mathrm{Co}$, and $\mathrm{Ni})$, acpy$\mathrm{mdtcH}$, and BA. Our first aim in this work was to obtain the 1D network coordination polymers which metal centers are bridged by the benzilic acid as mixed ligand. However, the benzilic acid present in the initial reaction mixture was not found in the crystalline product, except the solid product of $\mathbf{1}$. Unfortunately, attempts to obtain the product containing the benzilic acid and to improve yields by varying stoichiometry, temperature, and other reaction parameters proved to be generally unsuccessful. The formula of the solid product of $\mathbf{1}$ was identified as [Mn(acpy-mdtc)(BA)] containing benzilic acid by elemental analysis. Many attempts to prepare crystalline complex suitable for $\mathrm{x}$-ray diffraction were unsuccessful. The crystalline product of $\mathbf{2}$ was previously reported from the reaction of $\mathrm{Mn}\left(\mathrm{O}_{2} \mathrm{CCH}_{3}\right)_{2} \cdot 4 \mathrm{H}_{2} \mathrm{O}$ and acpymdtcH ligand in the methanolic solution. ${ }^{17}$ The crystallographic data were accordance with those for a previous compound. In complex $\mathbf{3}$, the oxidation state of cobalt is +3 in contrast to $\mathrm{Co}$ (II) of starting material. This oxidation to $\mathrm{Co}$ (III) can be assumed that the starting $\mathrm{Co}$ (II) salt undergoes aerial oxidation in the presence of the dithiocarbazate ligand in methanolic solution during preparation of the complex. $^{18}$

Description of the Structures. Ortep representations of the complex $\mathbf{3}$ and $\mathbf{4}$ with atom numbering schemes are

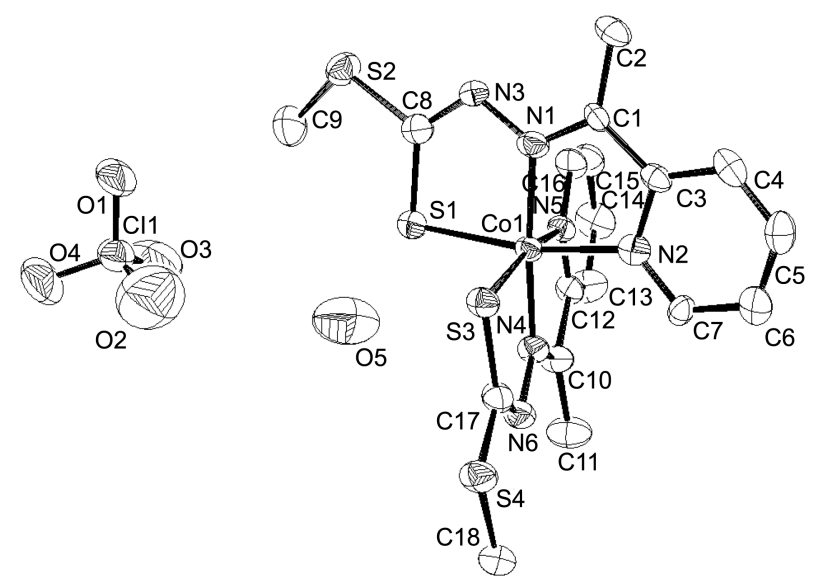

Figure 1. ORTEP diagram and atomic numbering scheme of the complex 3 (50\% thermal ellipsoids). Selected bond lengths $(\AA)$ and angles ( ${ }^{\circ}$ ): Co1-N1, 1.883(5); Co1-N2, 1.971(5); Co1-N4, 1.880(5); Co1-N5, 1.968(5); Co1-S1, 2.229(2); Co1-S3, 2.252(2); C8-S1, 1.729(6); C17-S3, 1.731(6); C8-N3, 1.302(8); C17-N6, 1.316(7); C1-N1, 1.294(7); N4-C10, 1.316(8); N1-Co1-N2, 82.0(2); N1Co1-N4, 174.5(2); N1-Co1-N5, 93.8(2); N1-Co1-S1, 86.4(2); N1Co1-S3, 99.1(2); N2-Co1-S1, 168.3(2); N5-Co1-S3, 166.9(1); S1Co1-S3, 91.5(1); N5-Co1-S1, 87.3(2); N2-Co1-N5, 95.0(2); N2Co1-S3, 88.9(2). 


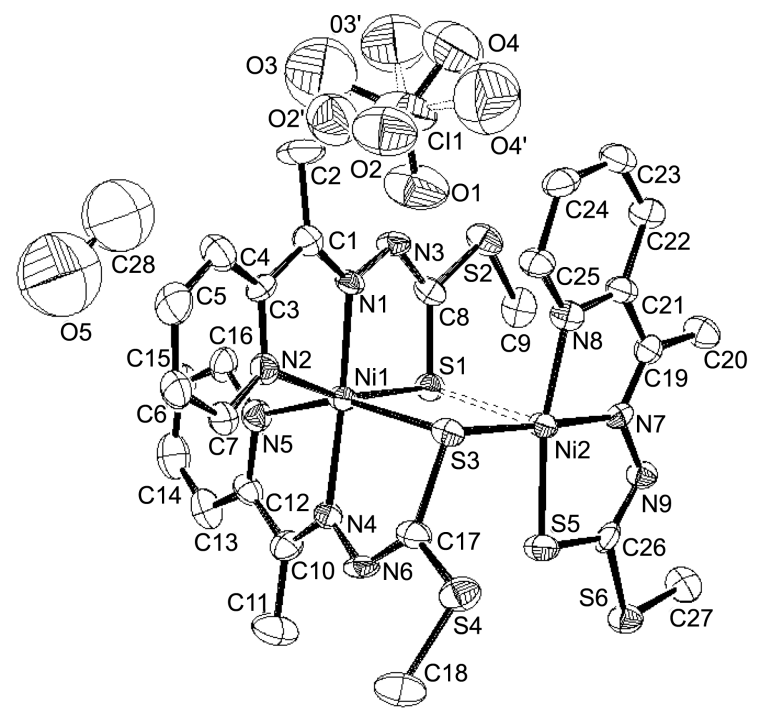

Figure 2. ORTEP diagram and atomic numbering scheme of the complex 4 (50\% thermal ellipsoids). Selected bond lengths $(\AA)$ and angles $\left({ }^{\circ}\right)$ : Ni1-N1, 1.995(5); Ni1-N4, 2.014(5); Ni1-N2, 2.084(6); Ni1-N5, 2.105(6); Ni1-S1, 2.399(2); Ni1-S3, 2.495(2); Ni2-N7, 1.860(5); Ni2-N8, 1.934(6); Ni2-S5, 2.163(2); Ni2-S3, 2.211(2); C8-S1, 1.705(7); C17-S3, 1.778(7); C8-N3, 1.314(3); C17-N6, 1.273(9); C1-N1, 1.286(9); N4-C10, 1.274(9); C26-S5, 1.736(7); C26-N9, 1.299(9); C19-N7, 1.287(9); N1-Ni1-N2, 78.9(2); N1Ni1-N4, 176.3(2); N1-Ni1-N5, 100.8(2); N1-Ni1-S1, 82.5(2); N1Ni1-S3, 100.5(2); N2-Ni1-S1, 161.5(2); N5-Ni1-S3, 158.7(2); S1Ni1-S3, 94.1(1); N2-Ni1-S3, 88.9(2); N2-Ni1-N5, 95.5(2); N5Ni1-S1, 88.2(2); N7-Ni2-N8, 83.1(2); N7-Ni2-S5, 86.5(2); S5Ni2-S3, 95.8(1); N8-Ni2-S3, 94.6(2); N8-Ni2-S5, 167.9(2); N7Ni2-S3, 177.7(2); Ni2-S3-Ni1, 94.9(1).

shown in Figure 1 and 2, respectively. The complex 3 consists of a $\left[\mathrm{Co}(\text { acpy-mdtc })_{2}\right]^{+}$cation, a $\mathrm{ClO}_{4}$ anion, and $0.5 \mathrm{~mol}$ $\mathrm{H}_{2} \mathrm{O}$ molecule. In $\left[\mathrm{Co}(\text { acpy-mdtc })_{2}\right]^{+}$cation, two molecules of the tridentate ligand coordinate to the $\mathrm{Co}$ (III) ion to form four five-membered chelate rings[Co1-N1-N3-C8-S1, Co1N1-C1-C3-N2, Co1-N4-N6-C17-S3, and Co1-N4-C10-C12N5]. The basal plane of the Co octahedral is defined by the two sulfur and two acetylpyridine ring nitrogen donors, while the apical positions are occupied by each azomethine nitrogen atoms. The angles at the cobalt center show large deviations from the ideal octahedral values of $90^{\circ}$ and $180^{\circ}$. Complex 3 shows the essentially similar to the structure of complex 2. ${ }^{17}$ However, the coordinate angles are much closer to the ideal octahedral than those in manganese complex: cis-L-M-L = 82.0(2)-99.1(2) and trans-L-M-L = 166.9(1)-174.5(2) for 3, cis-L-M-L = 71.0(1)-130.5(4) and trans-L-M-L = 146.7(1)-163.2(1) ${ }^{\circ}$ for 2 . The mean deviation (rms) of the basal plane N2N5S1S3 from the least-square plane is $0.22 \AA$, in contrary to the planes, N1S3N4N5 and N1N2N4S1 with mean deviation of 0.05 and $0.04 \AA$, respectively. The interplanar angles between these planes lie in the interval $87.76-88.82^{\circ}$. The tridentate ligands in the complex are almost planar (mean deviation $0.009 \AA$ ). The three individual rings, namely the acetylpyridine and the two five-membered chelate rings, are individually nearly planar (mean deviation 0.007-0.027 $\AA$ ) with small dihedral angles
(1.37-5.26 $)$ between them. The pair of coordinating ligands are nearly orthogonal to each other with the dihedral angle $82.91^{\circ}$. The Co-N [1.926(5) $\left.\AA\right]$ and Co-S [2.241(2) $\AA$ ] average bond lengths are similar to Co-N 1.942(3) and Co-S 2.222(1) $\AA$ of other six-coordinate distorted octahedral cobalt(III) complex of tridentate sulfur-nitrogen chelating agent, $\left[\mathrm{Co}(\mathrm{L})_{2}\right] \cdot 0.5 \mathrm{H}_{2} \mathrm{O}(\mathrm{L}=N$-2-mercaptophenyl-2'-pyridinecarboxamide, $\left.\mathrm{C}_{12} \mathrm{H}_{9} \mathrm{~N}_{2} \mathrm{OS}\right){ }^{19}$

Unlike the monomeric octahedral complex of $\mathbf{3}$, the complex 4 comprises of a dinuclear $\left[\mathrm{Ni}_{2}(\text { acpy-mdtc })_{3}\right]^{+}$cation, a $\mathrm{ClO}_{4}$ anion in which atoms $\mathrm{O} 2, \mathrm{O} 3, \mathrm{O} 4$ are disordered with site occupancies of 0.5 , and a $\mathrm{CH}_{3} \mathrm{OH}$ solvent molecule. The dimeric cation contains two geometrically distinct Ni(II) centers. Nil has a distorted octahedral geometry in which the equatorial positions are occupied by the two acetylpyridine nitrogens $[\mathrm{Ni1}-\mathrm{N}(\mathrm{av}), 2.095(6) \AA]$ and two thiolate sulfur atoms [Ni1-S(av), 2.448(2) $\AA]$ and the axial positions by two azomethine nitrogen atoms [Ni1-N(av), 2.005(5) $\AA$ ] from schiff base ligands whilst $\mathrm{Ni} 2$ has a predominantly square pyramidal geometry $\left[\mathrm{N}_{2} \mathrm{~S}_{3}\right.$ donor set: Ni2-N(av), $1.897(6)$ and Ni2-S(av), 2.412(2) $\AA]$ with $\tau=0.162$, $[\tau=\mid \beta-$ $\left.\alpha / 60^{\circ}\right]$, where $\beta$ and $\alpha$ are the two largest angles around the central atom; $\tau=0$ and 1 for the perfect square pyramidal and trigonal bipyramidal geometries, respectively. ${ }^{20,21}$ The two $\mathrm{Ni}(\mathrm{II})$ centers are doubly bound together by thiolate sulfur atoms of the deprotonated schiff base. The S1 atom weakly coordinated in the axial position with the distance of 2.862 (Ni2-S1), giving the square pyramid of $\mathrm{Ni}_{2} \mathrm{~N}_{2} \mathrm{~S}_{3}$. The distance between the two non-bonded Ni(II) centers is 3.473 $\AA$. The bond lengths are similar to those of other six-coordinate distorted octahedral nickel(II) complexes of tridentate sulfur-nitrogen donor ligands. [Ni(qaldsme $\left.)_{2}\right] \cdot 0.5 \mathrm{CH}_{3} \mathrm{CN}$ (GALDSME = anionic form of the 2-quinoline carboxyaldehyde schiff base of $S$-methyldithiocarbazate) ${ }^{22}[\mathrm{Ni}(\mathrm{L} 1)-$ (HL1) $\mathrm{ClO}_{4} \quad$ (L1 = S-methyl-3-((2-S-methyl-6-methyl-4pyrimidyl)methyl)dithiocarbazate) ${ }^{18}$ Although the dimeric $\mathrm{Zn}$ complex, $\left[\mathrm{Zn}(\mathrm{L})\left(\mu_{1,1}-\mathrm{N}_{3}\right) \mathrm{Zn}(\mathrm{L})\left(\mathrm{N}_{3}\right)\right] 1.5 \mathrm{H}_{2} \mathrm{O}\left(\mathrm{LH}=\left(\mathrm{OCH}_{3}\right)-\right.$ $\left.\left.(\mathrm{OH}) \mathrm{C}_{6} \mathrm{H}_{3} \mathrm{CHN}\left(\mathrm{CH}_{2}\right)_{2} \mathrm{~N}\left(\mathrm{CH}_{3}\right)_{2}\right]\right)$ are known, ${ }^{23}$ the complex 4, to our knowledge, is the first example of nickel(II) schiff base with two crystallographic independent $\mathrm{Ni}(\mathrm{II})$ centers in the asymmetric unit. Dimeric Ni(II) complex with 5- and 6coordination compared to $\mathrm{Mn}$ (II) and $\mathrm{Co}(\mathrm{III})$ presumably due to the different preferable coordination numbers: 4 or 6 for $\mathrm{Ni}$ and 6 for $\mathrm{Mn}$ (II) and $\mathrm{Co}(\mathrm{III}){ }^{24}$

In all the complexes the $\mathrm{C}(8)-\mathrm{S}(1)[\mathrm{C}(17)-\mathrm{S}(3)]$ bond distances appear to be longer than those reported for free thiosemicarbazones, such as 1.678(2) $\AA$ in 4-formylpyridinethiosemi carbazone ${ }^{25}$ and 1.684(4) $\AA$ in 2-keto-3-ethoxybutyraldehyde-bis(thiosemicarbazone). ${ }^{26}$ The $\mathrm{C}(8)-\mathrm{N}(3)$ $[\mathrm{C}(17)-\mathrm{N}(6)]$ and $\mathrm{C}(1)-\mathrm{N}(1)[\mathrm{C}(10)-\mathrm{N}(4)]$ bond distances show partial double bond character due to delocalization of $\pi$-electrons throughout the whole molecule ${ }^{27}$ where the ligand molecules exist in the deprotonated thiol form. Likewise, the double bond character in $\mathrm{C}(8)-\mathrm{N}(3)[\mathrm{C}(17)-$ $\mathrm{N}(6)]$ is quite obvious from the comparison of this length with that $[\mathrm{C}=\mathrm{N} 1.350(4) \AA]$ in the free ligand, $S$-benzyl-3((2-S-methyl-6-methyl-4-pyrimidyl)methyl)dithiocarbazate 
as thiol form. ${ }^{18}$ In the structures of $\mathbf{3}$ and $\mathbf{4}$ the sulfur and acetylpyridine nitrogen atoms are positioned cis to each other while the azomethine nitrogen atoms are trans oriented to each other, i.e., the ligands coordinate the metal in a meridional fashion. ${ }^{18,28,29}$

The IR spectrum of the free acpy-mdtcH has several prominent bands appearing at $c a .3149,1628$, and $1509 \mathrm{~cm}^{-1}$, due to $v(\mathrm{~N}-\mathrm{H}), v(\mathrm{C}=\mathrm{N})$, and $v(\mathrm{C}=\mathrm{S})$ stretching modes, respectively. ${ }^{30}$ On complexation for the complexes of $\mathbf{1 ,} \mathbf{3}$, and 4 , both bands of $v(\mathrm{~N}-\mathrm{H})$ and $v(\mathrm{C}=\mathrm{S})$ disappeared, and the $v(\mathrm{C}=\mathrm{N}$ ) band shifted to 1614 (for 1), 1600 (for 3), and $1599 \mathrm{~cm}^{-1}$ (for 4), respectively. These results indicate NNS coordination mode of the ligand in the thiol form. In addition, the bands $3111 \mathrm{~cm}^{-1}$ for 3 and $3421,3041 \mathrm{~cm}^{-1}$ for 4 can be assigned to the $\mathrm{H}_{2} \mathrm{O}$ for 3 and $\mathrm{CH}_{3} \mathrm{OH}$ molecule stretching vibrations for $\mathbf{4}$, respectively.

Thermal properties of the complexes were observed in flowing $\mathrm{N}_{2}$ atmosphere from room temperature to $800^{\circ} \mathrm{C}$. The complex 1 exhibits three steps of weight loss with two sharp exothermic peaks at 283 and $470{ }^{\circ} \mathrm{C}$ corresponding to the release of organic ligands in the temperature range of $216-751^{\circ} \mathrm{C}$. The total weight loss is $90.82 \%$, in good accordance with the calculated value $(89.15 \%)$. For complex $\mathbf{3}$, the first weight loss of $1.69 \%$ (calculated 1.46\%) from 210 to $250{ }^{\circ} \mathrm{C}$ with endothermic peak corresponds to the release of lattice water in the formula. Upon further heating up to $577{ }^{\circ} \mathrm{C}$, the sample loses an additional weight of $93.19 \%$ (calculated $88.97 \%$ ) corresponding to the loss of two acpymdtc ligand and a perchlorate anion in two steps overlapping each other. The decomposition in the range $250-311^{\circ} \mathrm{C}$ is very intense $\left(82.43 \%\right.$ ) while in the range $312-577{ }^{\circ} \mathrm{C}$ the mass loss $(10.76 \%)$ is slowing down. The pyrolysis of ligands is reflected by the intense exothermic effect on DTA curve with maximum at $309^{\circ} \mathrm{C}$ and $542{ }^{\circ} \mathrm{C}$, respectively. While, the complex 4 is stable up to $240{ }^{\circ} \mathrm{C}$ and then it undergoes three steps decomposition process for all organic ligands to $560{ }^{\circ} \mathrm{C}$. The total weight loss is $85.81 \%$ (calculated value $83.79 \%$ ). The DTA pattern shows three exothermic processes with the maximum at 250,362 , and 507 , respectively.

In conclusion, by the reactions of metal(II) ion and acpymdtcH in methanol solution, three NNS donor system complexes, [Mn(acpy-mdtc)(BA)] (1), [Co(acpy-mdtc $\left.)_{2}\right]-$ $\mathrm{ClO}_{4} \cdot 0.5 \mathrm{H}_{2} \mathrm{O}(3)$ and $\left.\left[\mathrm{Ni}_{2} \text { (acpy-mdtc) }\right)_{3}\right] \mathrm{ClO}_{4} \cdot \mathrm{CH}_{3} \mathrm{OH}(\mathbf{4})$ are isolated. It is noteworthy that two structurally different nickel(II) centers are connected through schiff base ligands in complex 4. This complex is, to our knowledge, the first example of dimeric nickel(II) schiff base complex.

Acknowledgments. This work was supported by the 2010 Research Fund of Catholic University of Daegu. The author also acknowledges the Korea Basic Science Institute for providing the crystal structure results.

\section{References}

1. Bermejo, E.; Carballo, R.; Castineiras, A.; Dominguez, R.; Liberta, A. E.; Maichle-Mossmer, C.; Salberg, M. M.; West, D. X. Eur. J. Inorg. Chem. 1999, 965.

2. Bermejo, E.; Carballo, R.; Castineiras, A.; Dominguez, R.; MaichleMossmer, C.; Strahle, J.; West, D. X. Polyhedron 1999, 18, 3695.

3. Rai, B. K.; Choudhary, P.; Rana, S.; Sahi, P. Orient. J. Chem. 2007, 23, 271.

4. Rodriguez-Argueelles, M. C.; Touron-Touceda, P.; Cao, R.; GarciaDeibe, A. M.; Pelagatti, P.; Pelizzi, C.; Zani, F. J. Inorg. Biochem. 2009, 103, 35

5. Shipman, C., Jr.; Smith, S. H.; Drach, J. C.; Klayman, D. L. Antiviral Res. 1986, 6, 197.

6. Klayman, D. L.; Bartosevich, J. F.; Griffin, T. S.; Mason, C. J.; Scovill, J. P. J. Med. Chem. 1979, 22, 855.

7. Klayman, D. L.; Scovill, J. P.; Bartosevich, J. F.; Mason, C. J. J. Med. Chem. 1979, 22, 1367.

8. Chan, J.; Amber, L. T.; Michael, W. J.; Josephine, M. P. Inorg. Chim. Acta 2010, 363, 1140.

9. Agrawal, K. C.; Sartorelli, A. C. Prog. Med. Chem. 1978, 15, 321.

10. Bal, T.; Atasever, B.; Solakoglu, Z.; Erdem-Kuruca, S.; Ulkuseven, B. Eur. J. Medicinal Chem. 2007, 42, 161.

11. Kovala-Demertzi, D.; Gangadharmath, U.; Demertzis, M. A.; Sanakis, Y. Inorg. Chem. Commun. 2005, 8, 619.

12. Yue, Y.-F.; Gao, E.-Q.; Fang, C.-J.; Xu, S.; Yan, C.-H.; J. Mol. Struct. 2007, 841, 67.

13. Karmakar, R.; Choudhury, C. R.; Hughes, D. L.; Yap, G.. P. A.; Fallah, M. S. El.; Desplanches, C.; Sutter, J.-P.; Mitra, S. Inorg. Chim. Acta 2006, 359, 1184.

14. Blessing, R. H. Acta Crystallogr. 1995, A51, 33.

15. Sheldrick, G. M. (2001). SHELXTL. Version 6. Bruker AXS Inc., Madison, Wisconsin, USA.

16. Farrugia, L. J. J. Appl. Cryst. 1997, 30, 565.

17. Mo, S. J.; Lim, W. T.; Koo, B. K. Bull. Korean Chem. Soc. 1998, 19, 1175 .

18. Roy, S.; Mandal, T. N.; Barik, A. K.; Pal, S.; Gupta, S.; Hazra, A.; Butcher, R. J.; Hunter, A. D.; Zeller, M.; Kar, S. K. Polyhedron 2007, 26, 2603.

19. Tyler, L. A.; Noveron, J. C.; Olmstead, M. M.; Mascharak, P. K. Inorg. Chem. 2000, 39, 357.

20. Addison, A. W.; Rao, T. N.; Reedijk, J.; van Rijn, J.; Verschoor, G. C. J. Chem. Soc., Dalton Trans. 1984, 1349.

21. Ray, A.; Banerjee, S.; Butcher, R. J.; Desplanches, C.; Mitra, S. Polyhedron 2008, 27, 2409.

22. Ali, M. A.; Mirza, A. H.; Bujang, F. H.; Hamid, M. H. S. A.; Bernhardt, P. V. Polyhedron 2006, 25, 3245.

23. Basak, S.; Sen, S.; Banerjee, S.; Mitra, S.; Rosair, G.; Rodriguez, M. T. G. Polyhedron 2007, 26, 5104.

24. Kolotilov, S. V.; Cador, O.; Golhen, S.; Shvets, O.; Ilyin, V. G.; Pavlishchuk, V. V.; Ouahab, L. Inorg. Chim. Acta 2007, 360, 1883.

25. Gabe, E. J.; Taylor, M. R.; Glusker, J. P. P.; Minkin, J.; Patterson, A. L. Acta Cryst., Sect. B 1969, 25, 1620.

26. Curtis, N. F., Melson, G. A., Eds.; Coordination Chemistry of Macrocyclic (24 of c) Compounds; Plenum: New York, 1979.

27. Mitra, A.; Banerjee, T.; Roychowdhury, P.; Chaudhuri, S.; Bera, P.; Saha, N. Polyhedron 1997, 16, 3735.

28. Barik, A. K.; Paul, S.; Kar, S. K.; Butcher, R. J.; Bryan, J. C. Polyhedron 1999, 18, 571.

29. Ali, M. A.; Majumder, S. M. M.; Butcher, R. J.; Jasinski, J. P.; Jasinski, J. M. Polyhedron 1997, 16, 2749.

30. Koo, B. K.; Jang, Y. J.; Lee, U. Bull. Korean Chem. Soc. 2003, 24 , 1014. 